\title{
Role of contextual activity in conditioning of voluntary response
}

\author{
IN-MAO LIU \\ NATIONAL TAIWAN UNIVERSITY
}

Conditioning of a voluntary response was studied by arranging a tone and a light as CS and UCS respectively with a CS-UCS interval of $200 \mathrm{msec}$. Ss in Group C were instructed to respond to the light by pressing a key (1250 gm of force, $6250 \mathrm{gm} \mathrm{cm}$ of work). Ss in Group E pressed to a prescribed extent to the CS (contextual activity of $500 \mathrm{gm}$ of force or $1000 \mathrm{gm} \mathrm{cm}$ of work) and completed the reaction in response to the UCS. It was found that far more CRs and more uniform results were obtained in Group $\mathrm{E}$, suggesting that, with the control of a certain contextual variable, results without exceptions may not be out of our reach.

Experiments on classical and instrumental conditioning procedures are characterized by their primary concern with the elicitation or evocation of a response under investigation. It is well known, however, that many problems have been raised as a result of confoundings by voluntary responses (e.g., Spence \& Ross, 1959; Hartman \& Ross, 1961) and attitudinal influences (Razran, 1935; Norris \& Grant, 1948; Moeller, 1954)。

In an effort to control the effects of voluntary responses and attitudinal influences in classical conditioning, the strategy tacitly employed so far has been to attempt to eliminate or neutralize them. The Ss are usually instructed to be relaxed and to respond in a natural way. Many studies (Freeman, 1948) on neuromuscular set, however, suggest the basic impossibility of this strategy. An implication is that all types of CRs may have at least some voluntary involvement. Thus a better way to proceed may be to study the effects of these voluntary processes. The technique for doing this employed in the present experiment is to provide a classical conditioning situation in which the contextual or background activity just preceding the UCR could be specified and measured.

\section{Method}

The Ss were 60 high school students. They were asked not to discuss their experience with others after the experiment. The main part of the apparatus, described elsewhere (Liu, 1966), consisted of a response key coupled to a weight of $500 \mathrm{gm}$ and to a spring connected with a polygraph recording pen by means of two strings passing over pulleys. When the response key was pressed downward to a given distance, the weight was lifted and the spring stretched to the same distance. Therefore, the work done by a force applied to the key could be measured in terms of energy. There was a second weight $(750 \mathrm{gm})$ above the first so that when the key was pressed to a dis- tance farther than the height of the second weight, both weights were lifted. The height of the second weight could be manipulated by an $E$ through a lever handle.

The $S$ was seated in a soundproof room. An airconditioner in the room produced a constant level of noise. Ss were divided into two groups in order of appearance. An $\mathrm{S}$ in one group (Group $\mathrm{E}$ ) was instructed to press as promptly as possible the $\mathrm{T}$-shaped key, upon hearing a tone (65 $\mathrm{dB} 200 \mathrm{msec}$.), to a $2-\mathrm{cm}$. distance. The pressing to this distance could be recognized by $S$, since the second weight $(750 \mathrm{gm})$ was $2 \mathrm{~cm}$ above the first (500 $\mathrm{gm})$ and, in order to press further, more than twice the original force was required. In Group E, S was instructed, further, to press the key all the way down when a light (which consisted of an illumination of a disk of $7.5 \mathrm{~cm}$ in diameter for 200msec. duration at eye level $50 \mathrm{~cm}$ away) appeared. Since the key protruded from the surface of a board (on which $S$ rested the heel of his hand) by $7 \mathrm{~cm}$, S's reaction to the light was to press the last $5 \mathrm{~cm}$ of the total distance. This required $1250 \mathrm{gm}$ of force. After pressing the key to its full distance, $S$ was instructed to allow the key to return to its initial position.

An $S$ in the other group (Group C) was told that he would hear a tone and see a light at various times during the experiment. When he saw the light, he was to react to it immediately by pressing the key. For this group, the key protruded from the surface of the board by $5 \mathrm{~cm}$, and the force of $1250 \mathrm{gm}$ was necessary to press the key. Therefore, the reaction to the light was exactly the same for this group as for Group E except that no reaction was required to the tone.

For each $\mathrm{S}$ in the two groups, the number of paired presentations of the tone and light was randomly selected from 4 to 7 , ending with a test trial in which the light was omitted. The number of paired presentations of the stimuli was not fixed, because we were afraid that Ss might inform one another even though they were told not to. The interstimulus interval between the onsets of the tone and light was $200 \mathrm{msec}$. Every time about $1.5 \mathrm{sec}$. before the onset of the tone, the polygraph motor started, serving as a ready signal. The average intertrial interval was $10 \mathrm{sec}$. If $\mathrm{S}$ 's reaction time to the light exceeded $300 \mathrm{msec}$. after two trials of training, that $S$ was immediately replaced. For this reason, three $\mathrm{Ss}$ in Group $\mathrm{C}$ and seven $\mathrm{Ss}$ in Group E were discarded.

\section{Results}

On the test trials, since the UCS light was omitted, any reaction to the $\mathrm{CS}$ tone for Group $\mathrm{C}$ was counted 
Table 1. Response Latencies (msec.)

\begin{tabular}{lllllll} 
Group & Stimulus & $F_{1^{*}}$ & $F_{2^{*}}$ & $L_{1^{*}}$ & $L_{2}{ }^{*}$ & Test \\
\hline E & Tone $(C S)$ & 367 & 204 & 180 & 178 & 188 \\
C & Light (UCS) 597 & 262 & 141 & 140 & $146^{* *}$ \\
& Light (UCS) & 312 & 162 & 123 & 107 & $72^{* *}$
\end{tabular}

${ }^{*} F_{1}$ and $F_{2}$ stand for the first two trials: $L_{1}$ and $L_{2}$, for the last two.

** The latencies were measured from the time of the tone cessation (uhich corresponded to the UCS onset on training trials). The aterage was taken on the data from CRs only.

as a CR. In Group E, if the key was pressed farther than $2 \mathrm{~cm}$, it was regarded as a CR. Because of the same position of the key, and the same force required for pressing the key, the CRs for the two groups were comparable.

CRs were obtained in 15 out of 27 Ss in Group C and in 22 out of $23 \mathrm{Ss}$ in Group $\mathrm{E}$. The difference in proportions of Ss giving the CRs in the two groups was highly significant according to the chi-square test $\left(X^{2}=10.48, \mathrm{df}=1, \mathrm{p}<.005\right)$.

Since pressing the key to a given distance would lift the weight and stretch the coil spring of the recording pen to the same distance, the work done in pressing the key could be calculated. The portion of the work done in stretching the coil spring of the recording pen was comparatively very small and hence omitted. Its possible maximum was less than $1 \mathrm{gm} \mathrm{cm}$. The average magnitudes of the CRs for Groups $\mathrm{E}$ and $\mathrm{C}$ were, respectively, 5565 and $2194 \mathrm{gm} \mathrm{cm}$. The above difference, using the Mann-Whitney test, was statistically highly significant $(p<.00006)$. It is also of interest to note that $46 \%$ of the CRs obtained in Group C were smaller in magnitude than the UCR; whereas, only $14 \%$ of them were smaller in Group E.

The fact that more CRs were obtained in Group $\mathrm{E}$ than in Group $\mathrm{C}$ might be attributed to shorter response latencies in Group $\mathrm{E}$. This conjecture is based on the observations from a preliminary experiment in which conditioning could not, in most Ss, be obtained with a CS-UCS interval of more than $300 \mathrm{msec}$. Therefore, the response latencies of the first two and last two trials together with those of the test trials were obtained from the polygraph recording. From Table 1 it is apparent that the more frequent CRs in Group $\mathrm{E}$ were definitely not because of shorter latencies of the CRs.

Discussion

The contextual activities just preceding the UCR for $\mathrm{Ss}$ in Group $\mathrm{C}$ were practically nil in terms of work. However, before seeing the UCS light, the Ss in this group could apply pressures of less than 1250 $\mathrm{gm}$ to the key, because pressures of less than $1250 \mathrm{gm}$ would not equally depress the key at all. In this sense of the contextual set, the amount of force on the key for the Ss in Group $\mathrm{C}$ was not controlled. The latter fact may explain the variable results obtained with Group C; about half of the Ss displayed CRs, and about half of the CRs were smaller in magnitude than the UCR. The condition of Group $\mathrm{C}$ is exactly that of classical conditioning experiments in which the contextual activity preceding the UCR is not specified or measured in terms of either force or work.

On the other hand, the condition for Group $\mathrm{E}$ was such that the contextual activity just preceding the UCR consisted of the work of $1000 \mathrm{gm} \mathrm{cm}$, or in terms of force, of $500 \mathrm{gm}$ of force. This accounts for the rather uniform results obtained with this group. Thus, $96 \%$ of Ss in this group showed CRs within from five to eight trials, and $86 \%$ of the CRs were equal in magnitude to the UCR。As was studied by various investigators cited in a previous paragraph, this points out the importance of the neuromuscular set or attitudinal factor consisting of the background activity on which a CR appears. Furthermore, it points out that once we can control and manipulate this critical variable, we are more likely to get uniform results without exceptions. The present finding parallels a recent study by Botwinick \& Thompson (1966) in which premotor time was found to be closely related to reaction time.

\section{References}

Botwinick, J., \& Thompson, L. W. Premotor and motor components of reaction time. J. exp. Psychol., 1966, 71, 9-15.

Freeman, G. L. Physiological psychology. New York: Van Nostrand, 1948

Hartman, T. F., \& Ross, L. E. An alternative criterion for the elimination of 'voluntary' responses in eyelid conditioning. $J$. exp. Psychol., 1961, 61, 334-338.

Liu, 1. Generalization and response latency. Percept. \& Psychophys., 1966, 1, 366-368.

Moeller, G. The CS-UCS interval in GSR conditioning. $J$. exp. Psychol., 1954, 48, 162-166.

Norris, E. B., \& Grant, D. A. Eyelid conditioning as affected by verbally induced inhibitory set and counter reinforcement. Amer. J. Psychol., 1948, 61, 37-49.

Razran, G. H. S. Conditioned responses: an experimental study and a theoretical analysis. Arch. Psychol., 1935, 28, No. 191. Spence, K. W., \& Ross, L. E. A methodological study of the form and latency of eyelid responses in conditioning. $J$. exp. Psychol., 1959, 58, 376-381.

\section{Note}

1. Supported by Grants FO5-TW-774-01 and 1 RO5 TW-00207-01 from the National Institutes of Health, United States Public Health Service. The assistance of Shang-wu Kuo is acknowledged. 